\title{
Good question, wrong answer
}

\author{
Nick Black professor of health services research
}

London School of Hygiene and Tropical Medicine, London WC1H 9SH, UK

\begin{abstract}
Although the extent to which national clinical databases publicly disclose comparisons of the quality of providers' care is an important question to answer, Tavare does not acknowledge that most of the leading databases already do this. ${ }^{1}$ These include, among others, adult critical care (Intensive Care National Audit and Research Centre's case mix programme database), severe trauma care (Trauma Audit and Research Network), lung cancer (National Lung Cancer Audit), neonatal intensive care (National Neonatal Audit), hip fracture (National Hip Fracture Database), coronary angioplasty, hip and knee replacement (National Patient Reported Outcome Measures programme), acute stroke care (Stroke Improvement National
\end{abstract}

Audit programme), and paediatric intensive care (Paediatric Intensive Care Audit Network).

Competing interests: NB chairs the Department of Health National Advisory Group for Clinical Audit and Enquiries and is a trustee of the Intensive Care National Audit and Research Centre

Tavare A. Where are we with transparency over performance of doctors and institutions? BMJ 2012;345:e4464. (3 July.)

Cite this as: BMJ 2012;345:e5055

(๑) BMJ Publishing Group Ltd 2012 